\title{
Comparative proteomic analysis of a new adaptive Pichia Stipitis strain to furfural, a lignocellulosic inhibitory compound
}

\author{
Xue-Cai Hao ${ }^{\dagger}$, Xiu-Shan Yang ${ }^{\dagger}$, Ping Wan and Shen Tian ${ }^{*}$
}

\begin{abstract}
The development of inhibitor-tolerant ethanologenic yeast is one of the most significant challenges facing bio-ethanol production. Adaptation of Pichia stipitis to inhibitors is one of the most efficient ways for dealing with inhibitor problems. The molecular mechanisms involved in the tolerance and adaptation of $P$. stipitis are, however, still unclear. In the present study, we developed a yeast strain from P. stipitis $Y 7$ that has improved tolerance against inhibitors. We performed comparative proteomic investigations with sodium dodecyl sulfate polyacrylamide gel electrophoresis and quadrupole time-of-flight mass spectrometry. These investigations gave insights into the tolerance of yeast strains to biomass conversion inhibitors at the protein level. Many proteins involved in glycolysis, the pentose phosphate pathway, and the tricarboxylic acid (TCA) cycle were found to be differentially expressed due to the presence of furfural. Quantitative real-time reverse transcription-PCR (RT-PCR) and metabolite analysis were utilized to provide orthogonal evidence for the results obtained. Our results provide a deeper understanding of the molecular mechanisms involved in the response of $P$. stipitis to furfural. These findings will benefit the design and development of inhibitor-tolerant yeast.
\end{abstract}

Keywords: Lignocellulosic ethanol, Furfural, P. stipitis, Stress tolerance

\section{Introduction}

The continued use of fossil fuels as a principal source of energy has led to a variety of environmental, economical and political concerns: as such, research into improving alternative and renewable energy strategies is of great importance. Bioethanol is one potentially viable alternative energy source. Bioethanol that is produced through the fermentation of lignocellulosic biomass from agricultural by-products, forest residues or energy crops offers many potential advantages in comparison to sugar- or starch-derived bioethanol, from both energetic and environmental points of view. Current methods of producing such bioethanol are not efficient, however, and the technology required in order to be able to use lignocellulosic biomass as a fermentation substrate faces several main challenges. One such challenge is the need for a

\footnotetext{
* Correspondence: cnu_tianshen@yahoo.com.cn

†Equal contributors

Enzyme and Fermentation Engineering Laboratory, College of Life Science,

Capital Normal University, 105 West Third Circle Road, Haidian, Beijing
} 100048, China robust fermentative microorganism that can tolerate the inhibitors present during lignocellulosic fermentation.

Inhibitors formed by acid-catalyzed hydrolysis of lignocelluloses, which include furan derivatives, weak acids, and phenolic compounds, reduce both the growth rate and fermentation of ethanologenic microorganisms [1]. Several different detoxification methods have been described and the effects on the chemical composition of lignocellulose hydrolysates have been investigated. Although detoxification improves the production of fuel ethanol, the fermentative activities, it is desirable, for economic reasons, to limit the number of additional steps required for detoxification. The development of inhibitor-tolerant ethanologenic yeast is therefore highly desirable for bioethanol production, but remains a major challenge.

Pichia stipitis is a well-studied, native xylose-fermenting yeast. The adaptation of $P$. stipitis to inhibitory hydrolysates is one of several possible strategies for dealing with inhibitor problems, offering an alternative to the use of detoxification methods. We previously developed a yeast strain from $P$. stipitis $\mathrm{Y} 7$ with improved tolerance 
against inhibitors that was able to ferment non-detoxified steam-exploded corn stalk with sufficient ethanol yield [2]. Further understanding of cellular stress responses to the individual inhibitor will enable the development of more tolerant strains as well as rapid and efficient fermentation of the hydrolysates.

Furfural is one of the major inhibitors in lignocellulosic hydrolysates. Many studies have shown that furfural can be converted by yeast to furfural alcohol [3-5]. The genetic mechanisms involved in furfural tolerance have been thoroughly researched. Through gene cloning and enzyme activity study, Liu et al. [6] found that the conversion of furfural is catalyzed by multiple aldehyde reductases. Traditional methods, such as metabolite, enzyme activity analysis, and kinetic analysis, can, however, analyze only one or a few metabolites, proteins or genes and are unable to globally assess the inhibition issue, which is complex and systematic [7]. The integration of different "omics" tools into the study of systems biology, including transcriptomics, proteomics, and metabolomics, provides an increasingly rich understanding of the response of microorganisms to various environmental perturbations $[8,9]$.

In the present study, comparative proteomic investigations with sodium dodecyl sulfate polyacrylamide gel electrophoresis and quadrupole time-of-flight mass spectrometry (Q-TOF MS) were performed, in order to give insights into the tolerance of ethanologenic yeast strains to biomass conversion inhibitors at the protein level,. These studies were performed with the aim of systematically identifying proteins through the use of adapted P. stipitis strain Y7 and to quantify the cells treated with furfural compared with control cells under oxygen-limited conditions. Quantitative real-time reverse transcriptionPCR (RT-PCR) and metabolite analysis were utilized to provide orthogonal evidence for the comparative proteome results.

\section{Results and discussion Adaptation}

The evolution of $P$. stipitis Y7 was encouraged using a directed adaption strategy incorporating specifically designed adaption media. The parent $P$. stipitis strain was challenged in the adaptation medium by increasing the concentration of furfural. After adaption of $P$. stipitis to the adaptation medium with $40 \mathrm{mM}$ furfural for fifty subcultures, a colony was isolated on solid medium and thereafter this strain was designated the adapted culture Y7-1. It was not possible to identify, macroscopically, any obvious gross phenotypic differences between the adapted culture Y7-1 and the parental culture Y7.

Figure 1 shows the growth of strains Y7-1 and Y7 in the defined medium, exposed to 10, 20, 30, and $40 \mathrm{mM}$ furfural respectively (A, B, C, and D). At $10 \mathrm{mM}, \mathrm{Y7}$ showed a lag phase of $8 \mathrm{~h}$. However, Y7-1 had only a $4 \mathrm{~h}$ lag time of cell growth and grew quickly into stationary phase in $24 \mathrm{~h}$. For cultures growing in $20 \mathrm{mM}$ furfuraltreated media, the lag time extended to $14 \mathrm{~h}$ and $8 \mathrm{~h}$ for strains $\mathrm{Y} 7$ and $\mathrm{Y} 7-1$, respectively. In the presence of $30 \mathrm{mM}$ furfural, the adapted strain had a 12-h lag phase and the parent strain had lag phases of $24 \mathrm{~h}$. Under exposure to $40 \mathrm{mM}$ furfural, the adapted strain grew into the logarithmic phase in $36 \mathrm{~h}$. At the same concentration, the parental strain showed no substantial cell growth.

\section{Batch fermentation on synthetic medium and non-detoxified enzymatic hydrolysate}

Table 1 summarizes the fermentation results for the defined medium containing either $30 \mathrm{mM}$ furfural or the enzymatic hydrolysate of non-detoxified steam-pretreated corn stover for both the parent strain and the adapted P. stipitis.

The adapted $P$. stipitis Y7-1 showed a good fermentation performance regardless of whether ethanol production was carried out on the medium or on the hydrolysate. The ethanol yield and productivity of Y7-1 fermented on the enzymatic hydrolysate of non-detoxified stem-pretreated corn stover were $0.43 \pm 0.03 \mathrm{~g}_{\mathrm{p}} \mathrm{g}_{\mathrm{s}}^{-1}$ and $0.41 \pm 0.03 \mathrm{~g}_{\mathrm{p} \mathrm{l}} \mathrm{l}^{-1} \mathrm{~h}^{-1}$, which represent increases of $19 \%$ and $46 \%$, respectively, compared to the parent strain. Similarly, the results from the defined medium fermentation by $P$. stipitis indicated that ethanol productivity was increased from $0.30 \pm 0.03 \mathrm{~g}_{\mathrm{p}}$ $\mathrm{l}^{-1} \mathrm{~h}^{-1}$ to $0.41 \pm 0.04 \mathrm{~g}_{\mathrm{p}} \mathrm{l}^{-1} \mathrm{~h}^{-1}$ after strain adaptation. This suggested that inhibitor tolerance was substantially enhanced in the adapted $P$. stipitis strain.

\section{Proteins differentially expressed in response to furfural}

The adapted yeast strain Y7-1 exhibited significant differences in growth and glucose metabolism compared to the parent yeast in the presence of furfural during the ethanol fermentation process. Many studies have reported that abundant changes in the expression levels of proteins, caused by the presence of furfural, were localized to most compartments and were found to be involved in almost all of the functions and pathways in yeast cells, suggesting that the response of yeast to furfural is global and systematic $[7,10]$.

In this study, the proteomic response of a P. stipitis strain following treatment with furfural was explored using LC-Q-TOF/MS. Proteins were identified through database searching and a total of 398 proteins were quantified. The relative protein expression levels were determined by using label-free MS quantification methods. As shown in Table 2, most of the differentially expressed proteins were involved in carbohydrate metabolism, most notably the glycolysis pathway and the alcohol catabolic process. 

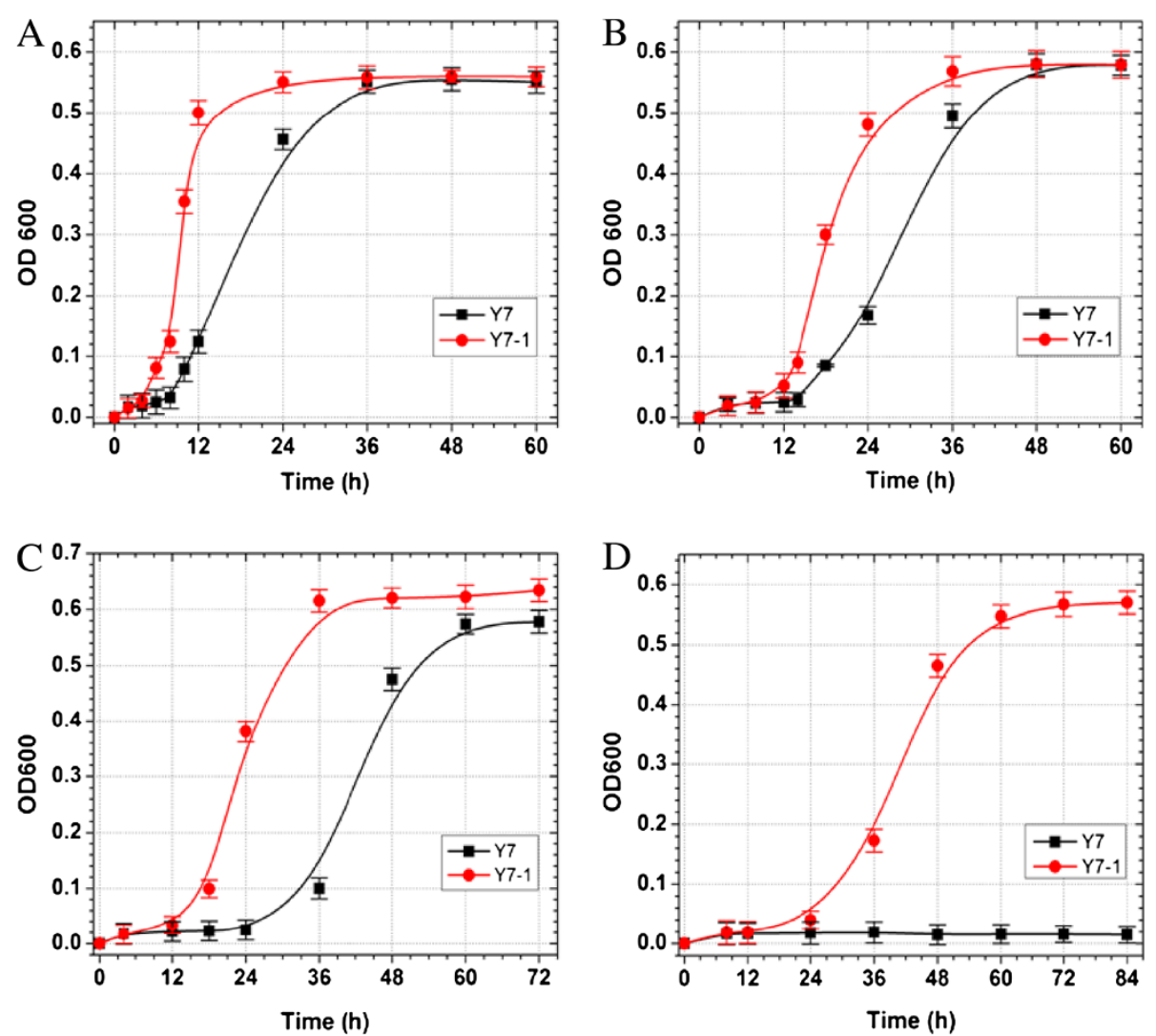

Figure 1 Cell growth of parental strain $Y 7$ and adapted strain $Y 7-1$ as measured at $\mathrm{OD}_{600}$ on the defined medium containing $10 \mathrm{Mm}$ (A), $20 \mathrm{mM}$ (B), $30 \mathrm{mM}$ (C) and $40 \mathrm{mM}$ (D) furfural.

After $4 \mathrm{~h}$ of furfural-treated cultivation, yeast cells were harvested during the lag phase, with the analysis showing that 17 proteins (Glk1p, Tdh1p, Pgk1p, Eno1p, Gnd1p, Adh1p, Adh3p, Adh4p, Adh6p, Cit1p, Tal1p, Idh1p, Idh2p, Fum2p, Aco1p, Gre2p, Mdh1p) had been dramatically up-regulated in Y7-1, all of which are involved in glycolysis (EMP), the pentose phosphate pathway (PPP), and the tricarboxylic acid (TCA) cycle.

The expression of Glk1p, Pgk1p and Enolp was significantly up-regulated. The expression levels of PFK $2 p$,
PDC1p, and PYK1p were not noticeably affected. It is assumed that glycolysis of the strain Y7-1 was activated following the up-regulated expression of Glk1p, Pgk1p and Eno1p, which played an increasingly important role in the glycolysis pathway. The suggestion that glycolysis is activated in the presence of furfural is supported by the results of a previous study of the conversion of furfural in aerobic and anaerobic bath cultures of $S$. cerevisiae CBS 8066 growing on glucose. This study showed that glycolysis-inducing changes in abundance are immediately

Table 1 Summaries of fermentation results from the parental and the adapted strains of $P$. stipitis ${ }^{a}$

\begin{tabular}{|c|c|c|c|c|}
\hline & \multicolumn{2}{|c|}{$\begin{array}{l}\text { Defined medium containing } 30 \mathrm{mM} \\
\text { furfural }\end{array}$} & \multicolumn{2}{|c|}{$\begin{array}{l}\text { Enzymatic hydrolysate of non-detoxified steam-pretreated } \\
\text { corn stover }\end{array}$} \\
\hline & Parent & Adapted & Parent & Adapted \\
\hline Ethanol yield on substrate $\left(g_{p} g_{s}^{-1}\right)$ & $0.36 \pm 0.02$ & $0.40 \pm 0.01$ & $0.36 \pm 0.01$ & $0.43 \pm 0.03$ \\
\hline Theoretical yield $(\%)^{\mathrm{b}}$ & $71.06 \pm 0.02$ & $78.14 \pm 0.07$ & $69.74 \pm 0.01$ & $83.33 \pm 0.03$ \\
\hline Ethanol productivity $\left(g_{p} L^{-1} h^{-1}\right)$ & $0.30 \pm 0.03$ & $0.41 \pm 0.04$ & $0.28 \pm 0.05$ & $0.41 \pm 0.03$ \\
\hline Fermentation time $(h)$ & 60 & 48 & 60 & 48 \\
\hline Maximum ethanol concentration $\left(g_{p} L^{-1}\right)$ & $17.76 \pm 0.03$ & $19.53 \pm 0.04$ & $16.80 \pm 0.05$ & $19.87 \pm 0.03$ \\
\hline Total sugar consumption rate $\left(\mathrm{g}_{i}^{-1} \mathrm{~L}^{-1} \mathrm{~h}^{-1}\right)$ & $0.82 \pm 0.04$ & $1.02 \pm 0.05$ & $0.79 \pm 0.04$ & $0.98 \pm 0.06$ \\
\hline
\end{tabular}

${ }^{a}$ The initial cell density for fermentation was $2.0 \mathrm{gL}^{-1}$

${ }^{b}$ Theoretical yield ethanol from glucose is $0.51 \mathrm{gpg}_{\mathrm{s}}^{-1}$; theoretical yield (\%) calculated as ethanol yield $\times 100$ divided by 0.51 . 
Table 2 Biological process analyses of the differentially expressed proteins according to Gene Ontology

\begin{tabular}{llll}
\hline GO.ID & \multicolumn{1}{c}{ Term } & Significant & p_value \\
\hline GO:0044262 & cellular carbohydrate metabolic process & 23 & 19 \\
GO:0005996 & monosaccharide metabolic process & 19 & 0.00013 \\
GO:0006066 & alcohol metabolic process & 19 & 0.0003 \\
GO:0006091 & generation of precursor metabolites and energy & 19 & 0.0003 \\
GO:0019318 & hexose metabolic process & 18 & 0.0003 \\
GO:0006006 & glucose metabolic process & 15 & 0.0003 \\
GO:0044282 & small molecule catabolic process & 14 & 0.00054 \\
GO:0006007 & glucose catabolic process & 14 & 0.00064 \\
GO:0016052 & carbohydrate catabolic process & 14 & 0.00116 \\
GO:0019320 & hexose catabolic process & 14 & 0.00116 \\
GO:0044275 & cellular carbohydrate catabolic process & 14 & 0.00116 \\
GO:0046164 & alcohol catabolic process & 14 & 0.00116 \\
GO:0046365 & monosaccharide catabolic process & 21 & 0.00116 \\
GO:0009056 & catabolic process & 25 & 0.00116 \\
GO:0005975 & carbohydrate metabolic process & 0.00127 \\
\hline
\end{tabular}

affected by furfural and that the reduction of furfural relied on active glycolysis [8]. The significantly induced expression of Tdh1p, Adh1p, Adh3p, Adh5p and Adh6p demonstrates that the reduction of furfural to furfural alcohol is likely catalyzed by alcohol dehydrogenases (ADHs) and multiple aldehyde reductases [11-13].

The pentose phosphate pathway (PPP) is an important carbohydrate metabolism pathway and is the main source of cytoplasmic NADPH. The expression levels of Gnd1p and Tal1p were found to be noticeably up-regulated, indicating that $P$. stipitis tolerance to furfural may be associated with activation of the initial stage of PPP. This suggestion is consistent with reports that gene deletion mutants of the pentose phosphate pathway (PPP) genes ZWF1, GND1, RPE1 and TKL1 exhibited growth deficiency in the presence of furfural [14].

The TCA cycle is a central metabolic pathway, generating ATP and NADH under aerobic conditions and also producing precursors for many compounds including some amino acids. The up-regulation of Cit1p, Idh1p, Idh2p, Fum2p, Aco1p and Mdh1p revealed that the TCA cycle can be activated in the presence of furfural to produce more $\mathrm{NAD}(\mathrm{P}) \mathrm{H}$, which allows the reduction of furfural. It has been reported that the presence of furfural in the medium results in a 50\% increase in the specific rate of the TCA cycle compared to the rate seen in furfural-free medium [15].

Although it has been mentioned before that the altered expression levels of most proteins catalyzing the reactions of the central carbon metabolism (with the exception of those involved in PPP) due to the addition of furfural can lead to the rearrangement of the central carbon metabolism in $S$. cerevisiae cells, which induces tolerance of furfural, there has been no previous study focusing on the stress effects caused in P. stipitis by the presence of furfural [7]. Our data suggest that $S$. cerevisiae and $P$. stipitis possess similarities in the process of converting furfural by activating the central carbon metabolism (EMP, PPP and TCA).

There are some proteins related to stress responses were also changed in the furfural-treated cultures. These proteins are involved in the response of yeast to oxidative stress, superoxide metabolic process, cell redox homeostasis. The superoxide dismutase Sod1p, glutathione peroxidase Gpx2p, thioredoxins Trx1p, and quinine oxidoreductase Qor1p were significantly up-regulated. However, expression of peroxisomal catalase Cat1p was down-regulated. The oxidative stress may be related to the decrease of the $\mathrm{NAD}^{+}$, and NADH levels. Although we do not clearly understand the mechanisms behind the response of these proteins to furfural, the different expression patterns of the proteins related to the stress response show that furfural may present a complex stress environment to the yeast cells which affects the expression levels of proteins related to stress response [10].

The quantitative RT-PCR results for the selected genes Although the protein expression level is influenced by protein turnover and post-translation modifications, the quantitative RT-PCR results provide orthogonal evidence of the reliability of the relative quantitative protein expression results. The transcript levels of the selected genes were measured by quantitative RT-PCR at $4 \mathrm{~h}, 6 \mathrm{~h}$ and $10 \mathrm{~h}$. As shown in Figure 2, at $4 \mathrm{~h}$ after furfural treatment, Y7-1 displayed gene expression profiles 


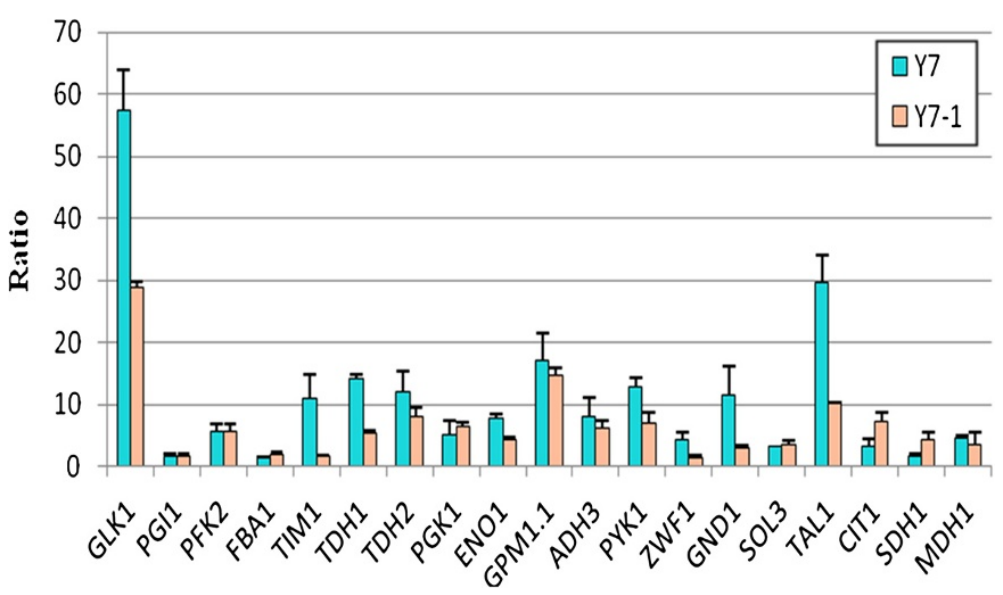

Figure 2 Comparison of transcript levels for selected genes in Y7 and Y7-1. The two strains were cultivated in flasks containing $100 \mathrm{ml}$ of the YPD medium (containing $10 \mathrm{mM}$ of furfural.liter ${ }^{-1}$ ) at $30^{\circ} \mathrm{C}$ and $150 \mathrm{rpm}$ for $4 \mathrm{~h}$. Mean values are presented with error bars representing variations of two standard deviations. The fold change was determined by the $2^{-\Delta \Delta c t}$ method.

distinct from the control Y7. At least 12 genes, including GLK1, TIM1, TDH1, TDH2, ENO1, GPM1.1, ADH3, PYK1, ZWF1, GND1, TAL1, and MDH1 demonstrated significantly higher levels of mRNA transcripts compared to that of the parental strain Y7. Many of these genes, such as TIM1, ZWF1, GND1, and TAL1, showed 3 -fold enhanced expression. GND1 and TIM1 showed more than 5-fold enhanced expression. The quantitative RT-PCR results for GLK1, GND1, TAL1, PGI1, PFK2, ENO1 and $M D H 1$ were consistent with the relative quantitative protein expression results. There were also discrepancies between the quantitative RT-PCR results and the relative quantitative protein expression results for genes such as PGK1, PYK1, ADH1, TDH3 and CIT1. It was also found, in both strains that many genes involved in the glycolysis and pentose phosphate pathways were repressed.

The response of yeast to furfural is a dynamic and complex process. As shown in Figure 3, at $4 \mathrm{~h}$ after furfural treatment, there was no significant difference in the expression of PGI1, PFK2 and FBA1 in either strain. The expression of GLK1, ZWF1, GND1 and SOL3 was up-regulated for Y7-1. The pentose phosphate pathway became the activated path for glucose metabolisms and furfural conversions for $\mathrm{Y} 7-1$ at the $4 \mathrm{~h}$ time point. Glycolysis and the pentose phosphate pathway are major routes for glucose metabolisms that provide energy and important intermediate metabolites for biosynthesis and ethanol production. Unfortunately, important enzymes involved in glycolysis were inhibited by furfural in the initial stage. It has been reported that $\mathrm{NAD}(\mathrm{P}) \mathrm{H}$ dependent aldehyde reductions, which involve multiple genes, is one mechanism through which the detoxification of furfural and HMF occurs [6]. The enhancements in these expressed genes are therefore significant for $\mathrm{NAD}(\mathrm{P}) \mathrm{H}$ regenerations in order to supply the cofactors that are needed for acetaldehyde conversion and for the reduction of furfural to occur. GND1, TAL1, ENO1, PYK1, ADH1 and $M D H 1$ displayed high activation levels for $Y 7-1$ at the $6 \mathrm{~h}$ time point in the presence of furfural.

The expression of many genes changed at the $4 \mathrm{~h}$ and $6 \mathrm{~h}$ time points. Y7 showed continued inhibition in cell growth and in the expression of many genes at the $6 \mathrm{~h}$ time point. Y7-1 was able to recover from the inhibitor challenge quickly within $4 \mathrm{~h}$. Transcription levels were low at $4 \mathrm{~h}$ for numerous genes (PGI1, FBA1, ENO1 and $A D H 1)$ in glycolysis and the pentose phosphate pathway for both strains. In Y7-1, many of these genes recovered to normal or near normal function levels at $6 \mathrm{~h}$. In contrast, in Y7, many genes continued to be repressed by the furfural at $6 \mathrm{~h}$. At $10 \mathrm{~h}$ after the furfural treatment, both strains recovered their normal growth patterns. Transcription levels of most genes in $\mathrm{Y} 7-1$ and $\mathrm{Y} 7$ displayed similar conditions at $10 \mathrm{~h}$, except PFK2, SOL3, and $T D H 3$, which remained up-regulated in Y7-1.

Furfural conversion to furan methanol and HMF to furan dimethanol are $\mathrm{NAD}(\mathrm{P}) \mathrm{H}$-dependent reduction activities that are controlled by multiple enzymes [16-18]. In our study, we investigated transcription dynamics during the lag phase in a major pathway involving glucose metabolism under furfural stress. Our results indicate that Y7-1 was able to withstand and quickly detoxify the furfural stress in situ, whilst producing ethanol, through both transcription responses and altered metabolic pathways.

\section{Conclusion}

The addition of furfural to the strain medium inhibits biomass growth, glucose consumption and ethanol production. Based on observations of a dose-dependent yeast response to furfural, we developed a directed 


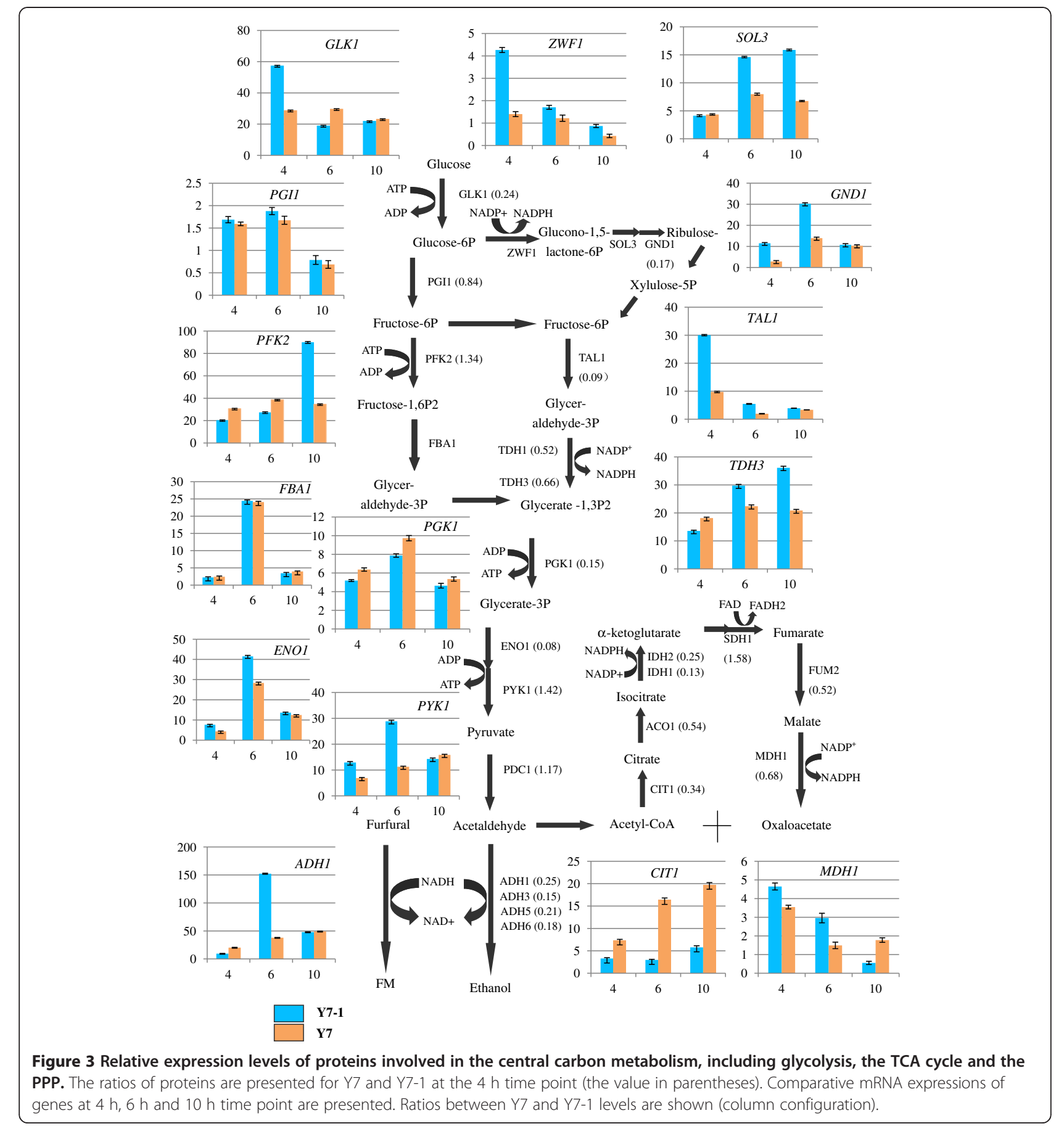

adaptation method and generated an adapted strain Y71. We evaluated the adapted ethanologenic yeast strain and demonstrated, under controlled conditions, significantly higher levels of tolerance to furfural compared with the parental strain. Adaptation can, therefore, be an effective means through which to improve microbial strains in this regard. The adapted, more tolerant, Y7-1 strain shows relatively high levels of tolerance to single inhibitors. The Y7-1 strain has also been tested against inhibitor complexes in biomass hydrolysate and has shown promise for use in biomass fermentation applications.

The proteomic data presented here provides a deeper understanding of the molecular mechanisms involved in the adaptation and response of $P$. stipitis to furfural. It was found, for example, that many proteins involved in glycolysis, the pentose phosphate pathway and the tricarboxylic acid (TCA) cycle were differentially expressed 
in the presence of furfural. It was found that furfural not only influences $P$. stipitis with respect to primary carbonate metabolic pathways but also causes the formation of a complex stress environment in yeast cells. Quantitative RT-PCR was utilized to provide orthogonal evidence supporting the comparative proteomics results. Our results suggest that continued efforts towards developing stress tolerant ethanologenic yeast to support a sustainable lignocellulosic biomass-to-ethanol industry are warranted.

\section{Materials and methods}

\section{Strains, media, and cultivation conditions}

Pichia stipitis Y7 is a strain that has recently been developed in our laboratory (Patent No.200810223301.5, CGMCC 2661). The detailed ethanol production profiles for Pichia stipitis $\mathrm{Y} 7$ have been reported elsewhere [2]. The yeast was cultured on a YPD plate containing $10 \mathrm{~g} / \mathrm{L}$ yeast extract, $20 \mathrm{~g} / \mathrm{L}$ peptone, $50 \mathrm{~g} / \mathrm{L}$ glucose, and $20 \mathrm{~g} / \mathrm{L}$ agar. The Y7 colony was grown in filter-sterilized media containing $10 \mathrm{~g} / \mathrm{L}$ yeast extract, $20 \mathrm{~g} / \mathrm{L}$ peptone, and $20 \mathrm{~g} / \mathrm{L}$ glucose. The inoculate culture was prepared using freshly grown cells harvested at the logarithmic growth phase and incubated with agitation of $150 \mathrm{rpm}$ for $18 \mathrm{~h}$ at $30^{\circ} \mathrm{C}$. Cell growth was determined by standard curves that related $600 \mathrm{~nm}$ absorbance to cell concentration (Agilent 8453, UV-visible Spectroscopy system, Agilent Technologies, Santa Clara, CA, USA).

\section{Adaptation experiment}

A directed adaptation method was developed and applied. P. stipitis Y7 strain was first maintained and cultured by sequentially transferring and growing cells in a medium containing low concentrations $(10 \mathrm{mM} / \mathrm{L})$ of furfural supplemented with $10 \mathrm{~g} / \mathrm{L}$ yeast extract, $2 \mathrm{~g} / \mathrm{L}$ peptone, $20 \mathrm{~g} / \mathrm{L}$ glucose. No additional nutrient salts or vitamins were added to the adaptation media. The inoculated culture was grown at $30^{\circ} \mathrm{C}$ with agitation at $150 \mathrm{rpm}$ on an orbital shaker. As the logarithmic growth phase was reached, surviving microorganisms were transferred to a fresh adaptation medium with a higher concentration (the concentration was gradually increased to $10 \mathrm{mM}, 20 \mathrm{mM}$, $30 \mathrm{mM}$ and $40 \mathrm{mM}$ furfural liter-1) This iterative process was repeated for higher inhibitor concentrations until the adapted culture was continuously subcultured across more than 50 subcultures. Following this process, the adapted strain Y7-1 was obtained.

\section{Batch fermentation}

The fermentation profiles of adapted $P$. stipitis were determined and compared with the parent strain by using inhibitor-treated synthetic medium and non-detoxified enzymatic hydrolysate. The defined medium contained $50 \mathrm{~g} / \mathrm{L}$ of glucose, $10 \mathrm{~g} / \mathrm{L}$ of yeast extract, $2 \mathrm{~g} / \mathrm{L}$ of peptone, and was supplemented with $30 \mathrm{mM}$ furfural. Enzymatic hydrolysate was produced from a pretreated solid cellulosic substrate of stem-exploded corn stover. (The steam-exploded pretreated corn stover was provided by the Henan Tianguan Group Co., Ltd (Henan, China) and contained $42.3 \%$ glucan, $0.16 \%$ furfural, $5.1 \%$ acetic acid). The pretreated solid substrate was diluted with sodium acetate buffer solution $(\mathrm{pH} 4.8)$ to $15 \%(\mathrm{w} / \mathrm{v})$ concentration. A mixture of Celluclast $1.5 \mathrm{~L}$ with an activity loading of approximately $15 \mathrm{FPU} / \mathrm{g}$ cellulose and Novozyme188 with an activity loading of approximately $20 \mathrm{IU} / \mathrm{g}$ cellulose was used. Additional nutrients were then added (yeast extract of $1 \mathrm{~g} / \mathrm{L}$ and peptone of $2 \mathrm{~g} / \mathrm{L}$ ). After 48 hours of hydrolysis at $50^{\circ} \mathrm{C}$ in a shaker set at $150 \mathrm{rpm}$, fermentation occurred. All fermentation experiments were performed at $30^{\circ} \mathrm{C}$, $90 \mathrm{rpm}$. The working volume was $100 \mathrm{~mL}$ and the initial cell concentration was $2 \mathrm{~g} / \mathrm{L}$. Samples were centrifuged at $10,000 \mathrm{rpm}$ for $5 \mathrm{~min}$ and were stored at $-4 \mathrm{C}$ until analyzed for sugar and ethanol.

Sugar concentration was measured using a highperformance liquid chromatography (HPLC) equipped with a KNAUER $\mathrm{NH}_{2}$ column (5-mm particle size, $250 \mathrm{~mm} \times 4.6 \mathrm{~mm}$ ) and a KNAUER RI detector (model K2301). Samples were run at a temperature of $30^{\circ} \mathrm{C}$ with a mobile phase of acetonitrile/ultrapure water at a flow rate of $1 \mathrm{ml} / \mathrm{min}$. Ethanol analysis of the fermentation broth was carried out using a gas chromatograph (GC, model 7890A, Agilent Technologies) through a headspace sampler (HS, model 7694E, Agilent Technologies) using an external standard for calibration. The chromatograph was equipped with a flame ionization detector and an Agilent HJ-PEG column of $30 \mathrm{~m}$ with an internal diameter of $0.32 \mathrm{~mm}$. Samples were run under the following conditions: column oven at $120^{\circ} \mathrm{C}$, front injection port at $200 \mathrm{C}$, with $\mathrm{N}_{2}$ as the carrier gas at a flow rate of $4 \mathrm{ml} / \mathrm{min}$.

\section{Sample preparation for proteomic analysis}

For the proteomic analysis, the parent strain $\mathrm{Y} 7$ and adapted strain Y7-1 were cultivated in flasks containing $100 \mathrm{ml}$ of the YPD medium (containing $10 \mathrm{mM}$ of furfural) at $30^{\circ} \mathrm{C}$ and $150 \mathrm{rpm}$ for $4 \mathrm{~h}$. Cells were harvested by centrifugation. To cause cell disruption, the cells were washed twice with cold water and suspended in $1 \mathrm{ml}$ of lysis buffer consisting of $20 \mathrm{mM}$ Tris- $\mathrm{HCl}(\mathrm{pH} 7.5)$, $250 \mathrm{mM}$ sucrose, $1 \%$ Triton X-100, and $10 \mathrm{mM}$ EDTA. Next, $1 \mathrm{mM}$ DTT and $1 \mathrm{mM}$ PMSF were added and sonicated ( $2 \mathrm{~s} / 2 \mathrm{~s}, 5 \mathrm{~min})$. The cell suspension was then vigorously mixed twice for $10 \mathrm{~min}$ and centrifuged in order to remove the undisrupted cells and debris and to obtain the crude extract. Supernatants were mixed with four volumes of $50 \%$ TCA-acetone at $-20^{\circ} \mathrm{C}$ for at least $2 \mathrm{~h}$ or preferably overnight. The precipitate was washed twice with icecooled acetone, and centrifuged at 17,000 $\times \mathrm{g}$ for $15 \mathrm{~min}$. 
The dried cytosolic proteins were dissolved in $40 \mu \mathrm{l}$ rehydration buffer (7.0 M urea, 2.0 M thiourea, 4.0\% (m/v) CHAPS, $50 \mathrm{mM}$ dithiothreitol (DTT), 0.5\% (v/v) immobilized pH gradient (IPG) buffer pH 4-7 (GE Healthcare) and small amounts of bromphenol blue). Protein content was determined according to the Bradford method.

\section{SDS polyacrylamide gel electrophoresis and in gel digestion}

The yeast protein samples were boiled for $5 \mathrm{~min}$ and then centrifuged. The yeast protein samples $(20 \mu \mathrm{g}$ of each sample) were mixed with loading buffer and separated on $12.5 \%$ SDS polyacrylamide gel electrophoresis gels. Electrophoresis was then performed until the dye front reached the bottom of the gel. Gels were stained using Coomassie brilliant blue R250. Each experiment was repeated at least twice.

Each of the protein bands from the stained polyacrylamide gels were excised and transferred into a $1.5 \mathrm{ml}$ centrifuge tube. The excised spots were destained by incubation in $100 \mu \mathrm{l}$ of $25 \mathrm{mM}$ ammonium bicarbonate/ $50 \%$ acetonitrile (more solution was added as necessary in order to immerse the gel particles) and were then vortexed for $10 \mathrm{~min}$. This wash/dehydration step was repeated up to 3 times. Dehydrated gel pieces were produced by adding acetonitrile $(100 \mu \mathrm{l})$, and then submitting them to air-drying for 5-10 min. Sufficient $10 \mathrm{mM}$ DTT solution was then added to cover the gel pieces and was reduced for $1 \mathrm{~h}$ at $56^{\circ} \mathrm{C}$. The same volume of $55 \mathrm{mM}$ iodoacetumide solution was added to replace the DTT solution, and the sample was incubated for $45 \mathrm{~min}$ at room temperature in the dark with occasional vortexing. The gel plugs were then rehydrated in $10 \mu \mathrm{l}$ of trypsin solution $(0.1 \mathrm{mg} / \mathrm{ml})$. Digestion was performed at $37^{\circ} \mathrm{C}$ for 12 to $16 \mathrm{~h}$. Sonication was used to extract digested peptides in the gel. Two additional extractions using $200 \mu \mathrm{l}$ of $5 \% \mathrm{FA} / 50 \%$ acetonitrile were performed. Each extracted sample was mixed in a tube and dried using vacuum freeze-drying.

\section{Metabolome analysis by LC-Q-TOF/MS}

Liquid chromatography coupled to time-of-flight mass spectrometry (LC-Q-TOF/MS) analysis was then performed on sample sets of parental and adaptive yeast strains. Samples were analyzed in a 4800 Proteomics Analyzer MALDI-TOF/TOF mass spectrometer (Applied Biosystems, Framingham, MA), in the $\mathrm{m} / \mathrm{z}$ range 850 4000 , in reflectron mode, with an accelerating voltage of $20 \mathrm{kV}$ and with a delayed extraction set to $120 \mathrm{~ns}$. All MS spectra were internally calibrated with peptides from trypsin autolysis. The MS analysis by MALDI-TOF/TOF mass spectrometry produces peptide mass fingerprints and the peptides observed with a Signal to Noise greater than 20 were collated and represented as a list of monoisotopic molecular weights.

Proteins ambiguously identified by peptide mass fingerprints were subjected to MS/MS sequencing analysis. Suitable precursors were selected from the MS spectra for the MS/MS analysis with CID on (atmospheric gas was used), using the $1 \mathrm{Kv}$ ion reflector mode and a precursor mass Windows $\pm 5 \mathrm{Da}$. The plate model and default calibration were optimized for the MS-MS spectra processing. For protein identification, the UniProt Knowledgebase Release 14.6 (UniProtKB/Swiss-Prot Release 56.6 of 16-Dec-2008, Uni-ProtKB/TrEMBL Release 39.6 of 16-Dec-2008) was searched using the MASCOT search engine v.2.1 (Matrix Science, London; http://www.matrixscience.com) through the Global Protein Server Explorer software v3.6 from Applied Biosystems.

\section{Real time PCR}

Y7 and Y7-1 were incubated on YPD medium (containing $10 \mathrm{mM}$ of furfural - liter-1). Yeast cells were harvested periodically starting from $4 \mathrm{~h}$ and then at $6 \mathrm{~h}$ and $10 \mathrm{~h}$. RNA was isolated by the Trizol method (Invitrogen, Carlsbad, CA). RNA cleanup was performed using a Qiagen RNeasy mini kit (Qiagen Sciences, MD). $10 \mu \mathrm{g}$ of total RNA was treated with DNase (Turbo-Free, Ambion) following the manufacturer's protocol, with the exception that an additional $1 \mu \mathrm{l}$ of enzyme was added after $20 \mathrm{~min}$ of incubation at $37^{\circ} \mathrm{C}$ for an additional $20 \mathrm{~min}$. The concentration of total RNA was determined by measuring absorbance at $260 \mathrm{~nm}$ (A260), with the quality of the RNA being assessed by determining the ratio of A260 to A280 and the use of agarose gel electrophoresis. Samples with RNA purity greater than 1.8 were used. cDNA was synthesized from $0.5 \mu \mathrm{g}$ total RNA using the Prime Script TM RT reagent kit (Perfect Real Time, TaKaRa) following the manufacturer's protocol.

The primers used in this study were designed using the free Primer 3 software. SYBR Premix Ex Taq TM (Perfect Real Time, TaKaRa) was applied for each qRTPCR reaction. For each reaction, a total of $20 \mu \mathrm{l}$ was used, consisting of $10 \mu \mathrm{l} 2 \mathrm{X}$ SYBR Green Master Mix, $0.6 \mu \mathrm{l}$ each of forward and reverse primer $(10 \mu \mathrm{M}), 1 \mu \mathrm{l}$ cDNA template and $7.8 \mu \mathrm{H}$ 2O. Amplifications were performed under the following conditions: $95^{\circ} \mathrm{C}$ for $3 \mathrm{~min} ; 40$ cycles of $95^{\circ} \mathrm{C}$ for $5 \mathrm{~s}, 58^{\circ} \mathrm{C}$ for $15 \mathrm{~s}$, and $72^{\circ} \mathrm{C}$ for $15 \mathrm{~s}$. At the end of the amplification cycle, a melting analysis was conducted to verify the specificity of the reaction. This was carried out by heating the amplification products from $55^{\circ} \mathrm{C}$ to $95^{\circ} \mathrm{C}$ at $0.5^{\circ} \mathrm{C} / 10 \mathrm{~s}$ and monitoring the decrease in fluorescence.

Expression levels were quantified by using a TaKaRa SYBR Green Real-Time PCR Master Mix (TaKaRa) in the iQ5 Real-Time PCR Detection System (Bio-Rad, USA), which was normalized using TUB2 expression 
levels as a reference. The fold change was determined by the $2^{-\Delta \Delta \mathrm{Ct}}$ method.

\section{Abbreviations \\ TCA: Tricarboxylic acid cycle; Q-TOF MS: Quadrupole time-of-flight mass spectrometry; ADHs: Alcohol dehydrogenases; PPP: Pentose phosphate pathway; EMP: Embden-Meyerhof-Parnas pathway; HMF: Hydroxymethyl- furaldehyde; NADPH: Nicotinamide adenine denucleotide phosphate reduced form; NADH: Nicotinamide adenine denucleotide reduced form.}

\section{Competing interests}

The authors declare that they have no competing financial interests.

\section{Authors' contributions}

ST and XSY conceived the project, designed the experiments, and wrote the manuscript. XCH and PW conducted the experiments and analyzed the data. ST supervised the project. All authors read and approved the final manuscript.

\section{Acknowledgements}

The authors acknowledge financial support received from the National Natural Science Foundation of China (No. 31100578) and the National Key Technology R\&D Program (No. 2011BAD22B01).

Received: 24 October 2012 Accepted: 28 February 2013

Published: 4 March 2013

\section{References}

1. Luo CD, Brink DL, Blanch HW: Identification of potential fermentation inhibitors in conversion of hybrid poplar hydrolyzate to ethanol. Biomass Bioenergy 2002, 22(2):125-138.

2. Shen T, Guixiong Z, Yan Fei Y, Yong YX: Yeast strains for ethanol production from lignocellulosic hydrolysates during in situ detoxification. Biotechnol Adv 2009, 27:656-660.

3. Morimoto S, Murakami M: Studies on fermentation products from aldehyde by microorganisms: the fermentative production of furfural alcohol from furfural by yeasts (part I). J Ferm Technol 1967, 45:442-446.

4. Villa GP, Bartroli R, Lopez R, Guerra M, Enrique M, Penas M, Rodriquez E, Redondo D, Iglesias I, Diaz I: Microbial transformation of furfural to furfuryl alcohol by Saccharomyces cerevisiae. Acta Biotechnol 1992, 12:509-512.

5. Liu ZL: Genomic adaptation of ethanologenic yeast to biomass conversion inhibitors. Appl Microbiol Biotechnol 2006, 73:27-36.

6. Lewis Liu Z, Moon J, Andersh BJ, Slininger PJ, Weber S: Multiple genemediated NADPH-dependent aldehyde reduction is a mechanism of in situ detoxification of furfural and 5-hydroxymethylfurfural by Saccharomyces cerevisiae. Appl Microbiol Biotechnol 2008, 81:743-753.

7. Feng-Ming L, Bin Q, Ying-Jin Y: Comparative Proteomic Analysis of Tolerance and Adaptation of Ethanologenic Saccharomyces cerevisiae to Furfural, a Lignocellulosic Inhibitory Compound. Appl Environ Microb 2009, 75(11):3765-3776.

8. Taherzadeh MJ, Gustafsson L, Niklasson C, Liden G: Conversion of furfural in aerobic and anaerobic batch fermentation of glucose by Saccharomyces cerevisiae. J Biosci Bioeng 1999, 87:169-174.

9. Xia JM, Lin FM, Yuan YJ: Systematic analysis of yeast response to inhibitors. Prog. Chem 2007, 19:1159-1163.

10. Feng-Ming Lin1, Ying Tan2 and Ying-Jin Yuan1: Temporal quantitative proteomics of Saccharomyces cerevisiae in response to a nonlethal concentration of furfural. Proteomics 2009, 9:5471-5483.

11. Diaz de Villegas, M. E., P. Villa, M. Guerra, E. Rodriguez, D. Redondo, and A. Martinez: Conversion of furfural into furfuryl alcohol by Saccharomyces cerevisiae. Acta Biotechnol 1992, 12:351-354.

12. Modig T, Liden G, Taherzadeh MJ: Inhibition effects of furfural on alcoho dehydrogenase, aldehyde dehydrogenase and pyruvate dehydrogenase. Biochem J 2002, 363:769-776.

13. Weigert B, Klein K, Rizzi M, Lauterbach C, Dellweg H: Influence of furfural on the aerobic growth of the yeast Pichia stipitis. Biotechnol Lett 1988, 10:895-900

14. S. W. Gorsich . B. S. Dien . N. N. Nichols . P. J. Slininger . Z. L. Liu . C. D: Skory Tolerance to furfural-induced stress is associated with pentose phosphate pathway genes ZWF1, GND1, RPE1, and TKL1 in Saccharomyces cerevisiae. Appl Microbiol Biotechnol 2006, 71:339-349.

15. Horva'th IS, Franzen CJ, Taherzadeh MJ, Niklasson C, Liden G: Effects of furfural on the respiratory metabolism of Saccharomyces cerevisiae in glucose-limited chemostats. Appl Environ Microbiol 2003, 69:4076-4086.

16. Petersson A, Almeida JR, Modig T, Karhumma K, Hahn-Ha"gerdal B, GorwaGrauslund MF: A 5-hydroxymethylfurfural reducing enzyme encoded by the Saccharomyces cerevisiae ADH6 gene conveys HMF tolerance. Yeast 2006, 23:455-464.

17. Song $\mathrm{M}$, Liu ZL: A linear discrete dynamic system model for temporal gene interaction and regulatory network influence in response to bioethanol conversion inhibitor HMF for ethanologenic yeast. Lect Notes Bioinfomatics 2007, 4532:77-95.

18. Song M, Ouyang Z, Liu ZL: Discrete dynamic system modeling for gene regulatory networks of HMF tolerance for ethanologenic yeast. IET Sys Biology 2009, 3:203-218.

doi:10.1186/1754-6834-6-34

Cite this article as: Hao et al:: Comparative proteomic analysis of a new adaptive Pichia Stipitis strain to furfural, a lignocellulosic inhibitory compound. Biotechnology for Biofuels 2013 6:34.

\section{Submit your next manuscript to BioMed Central and take full advantage of:}

- Convenient online submission

- Thorough peer review

- No space constraints or color figure charges

- Immediate publication on acceptance

- Inclusion in PubMed, CAS, Scopus and Google Scholar

- Research which is freely available for redistribution 